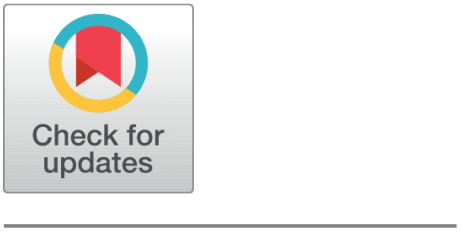

OPEN ACCESS

Received: 05.11.2020

Accepted: 26.04.2021

Published: 08.06.2021

Citation: Veerabhadrappa ST, Shivakumara Swamy PM, Suguna GC, Srinidhi SK, Priyanka D (2021) Continuous monitoring of Physiological parameters using PPG. Indian Journal of Science and Technology 14(20): 1689-1698. https ://doi.org/10.17485/IJST/v14i20.2011

* Corresponding author.

veerabhadrappast@jssateb.ac.in

Funding: None

Competing Interests: None

Copyright: (c) 2021 Veerabhadrappa et al. This is an open access article distributed under the terms of the Creative Commons Attribution License, which permits unrestricted use, distribution, and reproduction in any medium, provided the original author and source are credited.

Published By Indian Society for Education and Environment (iSee)

ISSN

Print: 0974-6846

Electronic: 0974-5645

\section{Continuous monitoring of Physiological parameters using PPG}

\author{
S T Veerabhadrappa ${ }^{1 *}$, P M Shivakumara Swamy¹, G C Suguna1 , S K Srinidhi ${ }^{1}$, \\ D Priyanka1
}

1 Department of Electronics and Communication Engineering, JSS Academy of Technical Education, Bengaluru, 560060, India

\section{Abstract}

Objectives: To develop a non-invasive measurement of continuous monitoring of hemoglobin using loT-enabled pulse oximetry. Currently in India, most women, senior citizens, and rural area people are suffering from anemia. In many cases, people unable to visit hospitals and laboratories for hemoglobin testing. To help the above people our proposed system will measure hemoglobin concentration without visiting the hospital at an affordable price. Methods: We developed real-time continuous monitoring of $\mathrm{Hb}$ concentration and oxygen saturation $\left(\mathrm{SpO}_{2}\right)$ using pulse oximetry. In this study, 47 healthy volunteers were participated and measure the above-mentioned parameters under resting conditions. Findings: The obtained results were in unison with laboratory measurements with the variation of $0.12 \mathrm{~g} / \mathrm{dL}$ to 1.0g/dL. Novelty/Applications: Experimental results showed the approach of continuous monitoring of hemoglobin and $\mathrm{SpO}_{2}$ using an loT-enabled noninvasive method can be useful in healthcare management.

Keywords: Hemoglobin; oxygen saturation; pulse oximetry; loT; Anaemia

\section{Introduction}

The most commonly used means of health monitoring involves the testing for physiologic vital signs. To more fully evaluate the physiological condition of an individual, it is essential to measure diagnostic parameters such as temperature, pulse rate, respiration rate, oxygen saturation $\left(\mathrm{SpO}_{2}\right)$, blood pressure (BP), blood sugar, and hemoglobin $(\mathrm{Hb})$ concentration ${ }^{(1)}$. Iron deficiency is one of the major causes that lead to anemia. Other minor causes include acute and chronic inflammation, parasite infections, red blood cell production or survival, and nutritional deficiencies ${ }^{(2,3)}$. When hemoglobin level decreases, due to the deformed shape of red blood cells, the patient feels weakness, fatigue, and drowsiness, which could lead to anemia. The hemoglobin of the individual varies depends on the person's gender, age, habits, and demographical region. The hemoglobin range of a healthy human is 13.5 to $17.5 \mathrm{~g} / \mathrm{dL}$ for men and 12.0 to $15.5 \mathrm{~g} / \mathrm{dL}$ for women. According to the statistics of a survey conducted by the World Health Organization, around $60 \%$ of the world's population is suffering from anemia which exceeds 1.6 million. As per the Global Nutrition Report 2017, 51\% of Indian women whose age is between 15 to 49 are anemic ${ }^{(4,5)}$. Current technology influenced a 
paradigm shift from invasive diagnostic measurements to non-invasive measurements results from rapid diagnosing the health condition of a patient. A typical example of an area that utilizes this methodology of disease diagnosis and treatment is a hospital ICU, wherein the parametric function values suggested by various monitoring devices are taken as one of the discrete criteria of assessing and asserting a patients' health status. Monitors currently used in Intensive Care Units (ICUs) provide information in a typical waveform and numerical values. The physiologic parameters currently displayed on ICU monitors include blood pressure, pulse waveform, ECG, oxygen saturation of the blood, heart rate, and respiratory rate. Though the data acquired from these devices are quite reliable in disease detection, and doctors consistently use them to monitor physiologic parameters to assure the patient's stability, they do inherently possess an undeniable constraint of inaccessibility to the underprivileged masses of the society. Thus, any attempt to modernize, innovate or improve these devices necessarily involves developing new techniques to mitigate the aforementioned negatives. One effective way of implementing the same is by incorporating the ideology of the Internet of Things (IoT) in these devices ${ }^{(6)}$. Enabling IoT in these devices points in the direction wherein all vital devices are linked to a common hub or server and collectively share information among them. The establishment of such an interconnected monitoring network allows to helping critical patients, requiring continuous monitoring, to be evaluated regularly, within the comfort zones of their houses, thereby reducing the incurred cost involved with the process, when the same is done within an ICU front.

The article attempts for IoT - enabled measuring devices such as pulse oximeter, pulse rate monitoring, respiration rate monitoring, body temperature, and hemoglobin. The basic parametric values obtained, then immediately confronted by an analog front, wherein a set of complex algorithmic computations employed to assess the same and compare it with a set of predefined medical thresholds. A fall or rise of the measured values beyond these limiting thresholds is indeed a clear indication of a medical emergency, during which the patient under concern must be provided with required treatment and care support. The urgency to address such situations is profoundly solved by the usage of an SMS, which will send a timely alert message to the doctor or concerned professional citing the case, need of an emergency ${ }^{(7)}$. Moreover, the output obtained from the system is then fed to a cloud server with IoT capabilities which further strengthens the practicality of the monitoring scheme in the modern tech-savvy world. The addition of IoT capabilities to the considered design promotes its essential feature of interconnected networks, which allows real-time monitoring and analysis of the captured data point values. The fundamental idea of interconnected networks allows real-time data to be stored in a web-based server for continuous and efficient monitoring of signals with much visual appeal on any connected device ${ }^{(8)}$.

The measurement of pulse rate and hemoglobin are most frequently performed laboratory tests and physical examination in many cases such as underweight children, during pregnancy, injury, and post-operative conditions ${ }^{(9-15)}$. Measurement of hemoglobin concentration provides in the total oxygen-carrying ability in the human body. Deficiency in hemoglobin leads to anemia, the reduction of iron content in blood, which creates problems related to kidney and liver whereas higher levels of hemoglobin result in polycythemia. Currently, various invasive methods are used to measure Hb concentration, such ashemoase, cyanmeth, copper sulphur gravimetric method, and automated hematology analyzer ${ }^{(16,17)}$. But for all of these invasive methods, a drop of blood is required and these samples are later analyzed. Currently, measurement of $\mathrm{Hb}$ is an invasive method where, blood is drawn for the patients, accurate and it has its limitations, such as delay in therapeutic plan. A noninvasive method is pain-free, minimum risk of infection, more instantaneously, and also facilitates real-time data monitoring by allowing an immediate clinical reaction to the measured data. SpHb method reported accurate $\mathrm{Hb}$ measurements and keeps track of continuous monitoring of bleeding in patients and also helped in the detection of anemia ${ }^{(18)}$. Many researchers demonstrated decreased accuracy during blood loss and also detect a decrease in $\mathrm{Hb}$ level in dynamic situations and also indicate the appropriate timing for further $\mathrm{Hb}$ measurements ${ }^{(19-23)}$. Several studies have shown that the need for blood transfusions can be significantly reduced during surgery with the help of constant monitoring of the hemoglobin level ${ }^{(24-27)}$. The measurement of $\mathrm{Hb}$ noninvasively allows for a high-speed assessment of a patient's condition and the need for transfusion which enables prompt and appropriate clinical management. Hemoglobin level in a person's blood can be evaluated by analyzing the color of the blood ${ }^{(28)}$ and the results are obtained between 30 and 60 seconds, allowing immediate clinical assessments. Because of the advancement of technology and research, such as spectrophotometry, opt acoustic and transmission spectroscopy, many low-cost and simple non-invasive technologies have emerged. Several researchers had discussed the uses of multi-wavelength pulse oximeters to detect hemoglobin levels, and $\mathrm{SpO}_{2}{ }^{(29-32)}$. Macknet et al. evaluated $\mathrm{Hb}$ measurement with hemodilution and compared it with pulse $\mathrm{CO}$-Oximeters and invasive laboratory $\mathrm{CO}$-Oximeter $\mathrm{Hb}$ measurements which were carried out in both healthy and surgical subjects ${ }^{(33)}$. Lionel Lamhaut et al. measured $\mathrm{Hb}$ simultaneously of adult patients during major urologic surgery by using Pulse CO-Oximetry, HemoCue, and Automated Laboratory Hemoglobin Measurement. Obtained results were similar and also established a good correlation between Pulse CO-Oximetry, HemoCue methods using a linear regression ${ }^{(34)}$. Gregor Lindner et al. have shown Pulse CO-Oximetry is a most promising noninvasive technique and also compared with laboratory results (capillary method) with higher accuracy in most of the settings ${ }^{(35)}$. McMurdy et al. found that the use of 
diffuse reflectance spectroscopy on the conjunctiva improves the diagnosis over observational studies ${ }^{(36)}$. Esenaliev et al. had reported real-time measurement of $\mathrm{Hb}$ with opt acoustic which has greater potential than other non-invasive methods ${ }^{(37)}$. Abay TY et al. discussed NIRS techniques for the measurement of relative hemoglobin concentration, oxygen concentration using PPG signal ${ }^{(38)}$. Several researchers had implemented an android-based health monitoring system to measure vital parameters such as $\mathrm{SpO}_{2}$, heart rate, temperature ${ }^{(39)}$, blood glucose ${ }^{(40)}$, hypertension ${ }^{(41)}$, and continuous monitoring of physiological signals during sleep ${ }^{(42)}$. Kadarina et al. implemented a remote monitoring device to measure heart rate, $\mathrm{SpO}_{2}$ of mother and child using Thingboard. Evaluated $\mathrm{SpO}_{2}$ values for mild, moderate, and severe hypoxia ${ }^{(43)}$. Several researchers have developed a remote health monitoring system using wireless sensors technology and IoT to monitor several patients at a time ${ }^{(44-46)}$. Blood pressure was estimated using pulse arrival time of PPG signal ${ }^{(47)}$ and machine learning techniques ${ }^{(48)}$.

The proposed method continuously monitors the heart rate, $\mathrm{SpO}_{2}$, and hemoglobin concentration of the subject using 600 $\mathrm{nm}$ and $940 \mathrm{~nm}$ wavelengths. The paper further catalogs the typical system design, data analysis and methods, results, and related discussions for the envisioned design schematic.

\section{Materials and Methods}

The prime objective of the work is to enable the applicability of basic health monitoring facilities at a household level coupled with the essential benefits of IoT-enabled services. The proposed work self-enlists the vital body parameter measuring devices used in a conventional high-tech hospital, each enabled with IoT services and thereby feeding the collective vital information to a central monitoring hub. The basic functional architecture of the proposed design has both hardware and software constituents, as shown in Figure 1. The prospect of the project also envisions the feature of possessing technologies that alert us, of systems or devices that are in danger of failing, thus forming an intelligent connected network of the healthcare system that can essentially never be down.

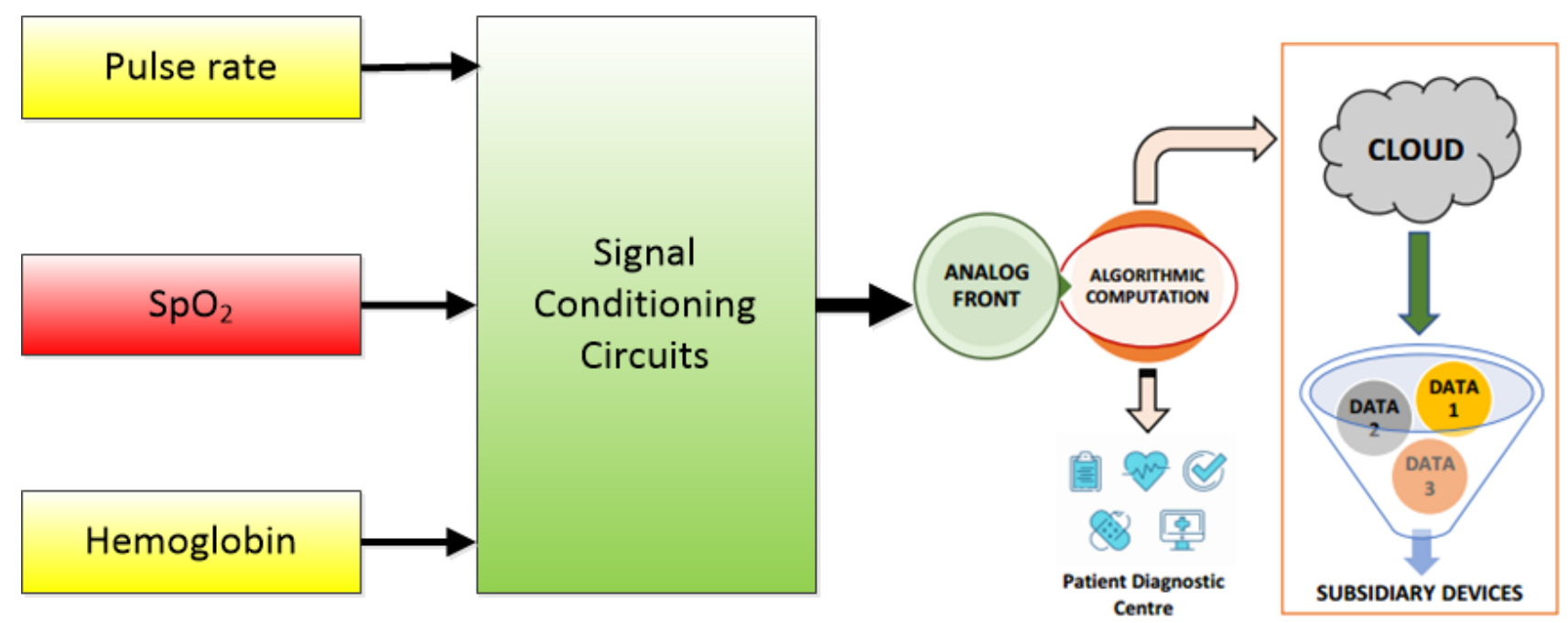

Fig 1. Block diagram of a health monitoring device

Pulse oximetry is the non-invasive measurement of oxygen saturation $\left(\mathrm{SpO}_{2}\right)$. It is based on the concept that arterial oxygen saturation can be determined by using two wavelengths (oxygenated hemoglobin and deoxygenated hemoglobin), provided the measurements are made on the pulsatile part of the waveform. This non-invasive method of multi-spectral measurement is based on radiation of nearly monochromatic light, emitted by Light Emitting Diodes (LED) in the range of 600nm to 1400nm, through an area of skin on the finger. Hemoglobin is non-invasively measured using red blood cells (RBCs) of the arterial pulse signal. The above-mentioned observations, proven by clinical experience, are based on the following: Light passing through the ear or finger will be absorbed by skin pigments, tissue, cartilage, arterial blood, and venous blood. The absorbance is additive and obeys the Beer-Lambert Law defined as

$$
A=-\log T=\log \frac{I_{o}}{I}=\varepsilon D C
$$


Where lo - incident light intensity, 1 - transmitted light intensity, $\varepsilon$ - Extinction coefficient , D - Depth of the absorbing layer and $\mathrm{C}$ is concentration.

Most of the absorbance is fixed and does not change with time. Under steady-state metabolic circumstances, the composition and flow of blood in the capillaries are constant, at least over a short time. Only the blood flow in the arteries and arterioles is pulsatile.

Therefore, measuring the changing pulse wave only measures the absorbance due to arterial blood and also allows determining the arterial oxygen saturation $\left(\mathrm{SpO}_{2}\right)$ and hemoglobin. The concentration of Deoxygenated hemoglobin (Hb) and Oxygenated hemoglobin $\left(\mathrm{HbO}_{2}\right)$ affects the bloodstream, whose absorption coefficients are $660 \mathrm{~nm}$ (red light spectra) and $940 \mathrm{~nm}$ (infrared light spectra) respectively. A photodiode is used to measure the absorption of these selected wavelengths of light passing through living tissue as shown in Figure 2, used in pulse oximeters.

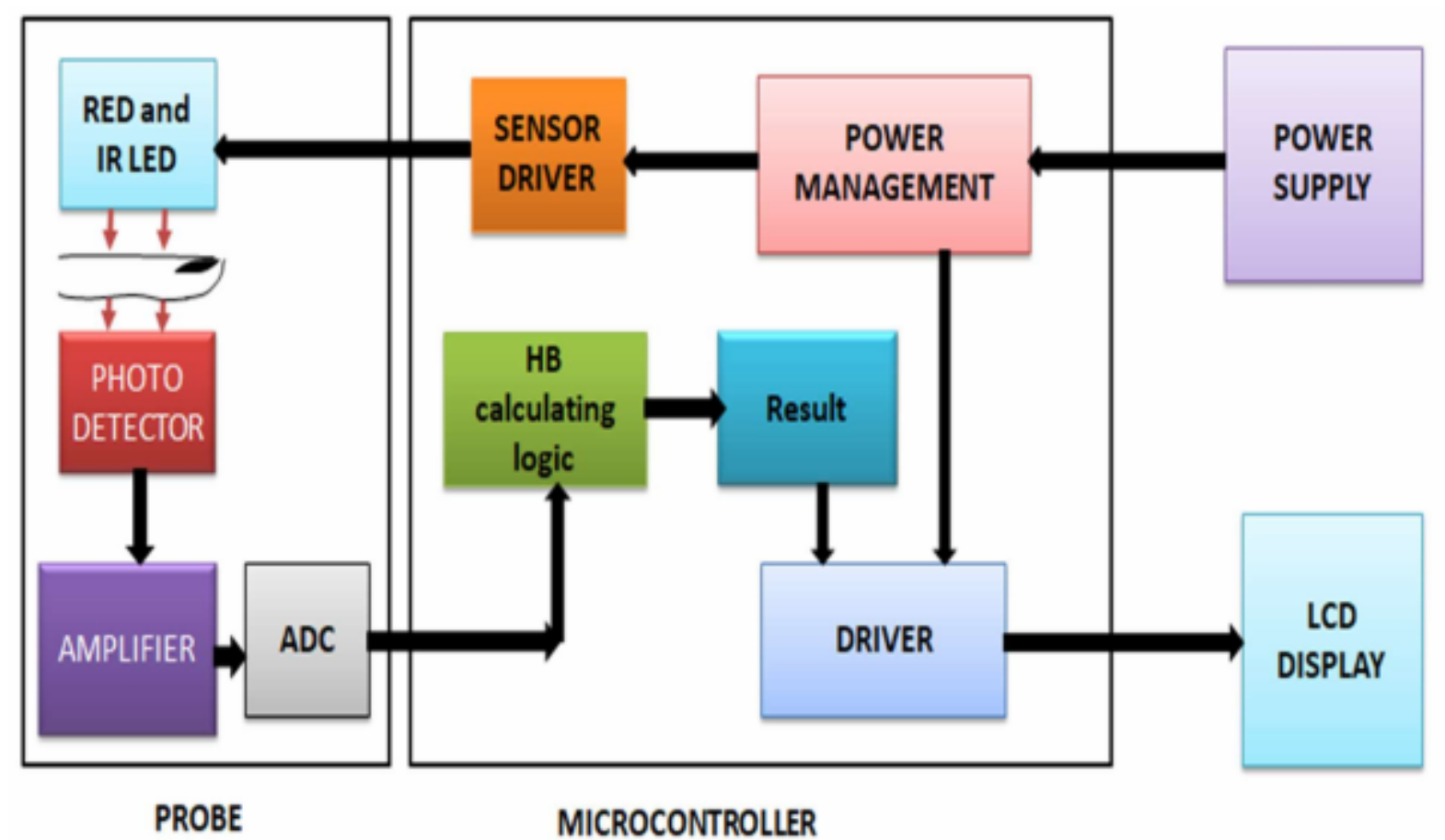

Fig 2. Block diagram of the estimation of parameters using pulse oximetry

Pulse oximetry is based on an optical technique used for the continuous monitoring of hemoglobin and oxygen saturation in arterial blood. Pulse oximetry has two LED's IR (940nm) and RED (660nm), photosensor and has a high-performance analog front end to detect physiological and pulse oximetry signals. These two wavelengths are selected because at $660 \mathrm{~nm}$ wavelength absorbance of deoxyhemoglobin is greater than the absorbance of oxyhemoglobin whereas at $940 \mathrm{~nm}$ wavelength absorbance of oxyhemoglobin greatly exceeds the absorbance of deoxyhemoglobin. Both LEDs are switched ON and OFF alternatively for a short interval of $250 \mathrm{msec}$ through the I/O pins of the microcontroller for measurements. The sensor is designed in transmittance mode with RED and IR LEDs fitted on the upper part of the finger clip and photodiode on the lower part. The index finger is inserted into the designed probe for the $\mathrm{Hb}$ detection process. The light transmitted through the finger falls on the photodiode and the output of the photodiode is fed to the analog pin of the microcontroller for analog to digital conversion after amplification. Output voltage increases linearly with the intensity of light. The microcontroller is programmed to calculate the continuous monitoring $\mathrm{Hb}, \mathrm{SpO}_{2}$, heart rate, and display the same on LCD, and data is fed to a cloud server with IoT capabilities which further strengthens the practicality of the monitoring scheme.

\subsection{Subjects}

This study was carried out involving 18 male ( $42.3 \pm 4.504$ years) and 29 female ( $37.6 \pm 6.234$ years) volunteers, with an average age of 39.6 years. None of the subjects had any history of the disease. The volunteers were allowed to rest for 3 to 5 minutes before the study. The pulse signals from the test subjects were recorded under normal breathing conditions. The pre-processing 
and data analysis was carried out using Python. It may be mentioned here, that all the volunteers were explained and made aware of the details of the experimental protocol. Further, all the volunteers had given written consent for the collection of data.

\subsection{Methodology}

The index finger is inserted into the designed pulse oximeters probe for detection of pulse rate, oxygen saturation and hemoglobin of the volunteers is as shown in Figure 3. The light transmitted through the finger falls on the photodiode and the output of the photodiode is connected to the controller through ADC. The pulse signals are sampled at a sampling frequency of $500 \mathrm{~Hz}$ with a resolution of 16 bits per sample.

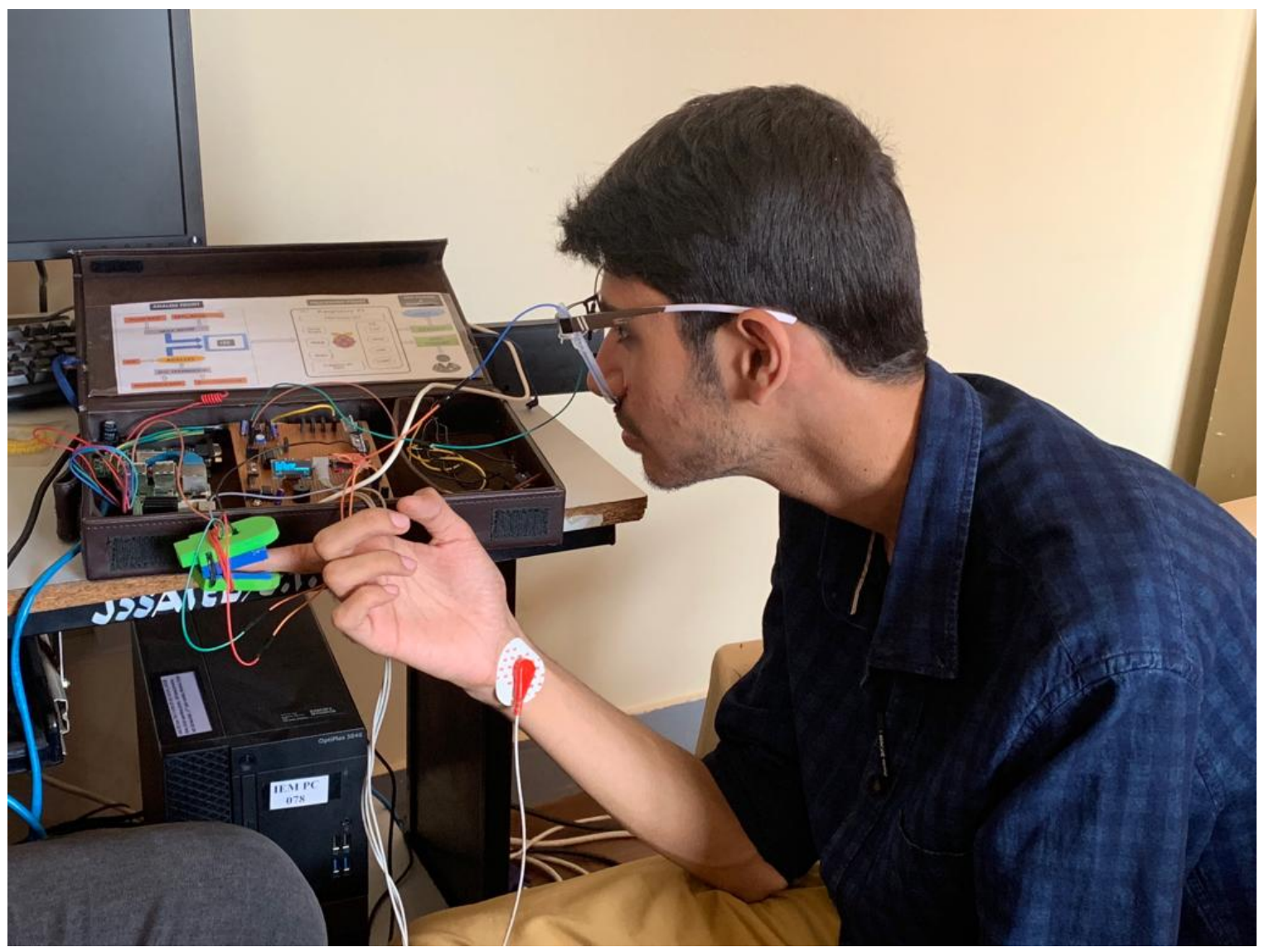

Fig 3. Hardware design and computation of the vital parameters

\subsection{Estimation of pulse rate and Oxygen saturation $\left(S_{p} \mathbf{O}_{2}\right)$}

The typical pulse waveform and feature points are as shown in Figure 4. These features are obtained from changes in beat-tobeat, such as the peak amplitude of the percussion wave (h1), the amplitude of the valley point (h2) measured from the foot and $\mathrm{t} 2$ and $\mathrm{t} 3$ respective time instants. The points a1, a2, and $\mathrm{a} 3$ are the onset, peak, and dicrotic notch of the pulse. The difference between point a 1 and 22 is peak amplitude (h1) and a1 and a 3 is notch amplitude (h2) of the pulse. Pulse period (T) is the time difference between peaks of the percussion wave or onset of diastolic waves ${ }^{(36)}$. From simple shape pulse analysis and derived mathematical parameters can be related to the physiological and clinical characteristics to identify cardiovascular pathologies. The pulse rate in BPM is computed by using the formula

$$
\text { Pulse rate }=\frac{60}{T} B P M
$$

Pulse oximeters are low-cost, non-invasive medical sensors that are used to continuously measure the $\mathrm{SpO}_{2}$ of hemoglobin in the blood. The red and infrared component is corresponding to oxygenated and deoxygenated hemoglobin components of 


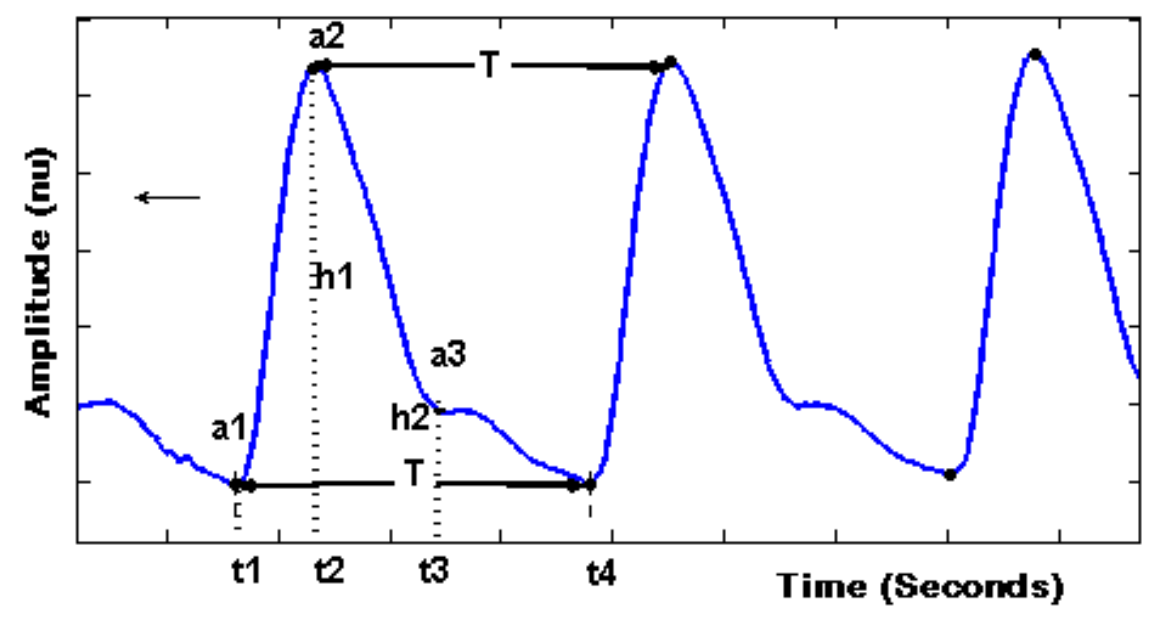

Fig 4. Typical pulse waveform and its characteristics

the blood respectively and is shown in Figure 5. The $\mathrm{SpO}_{2}$ is calculated based on red and infrared components of pulse oximetry. It measures and displays the percentage of oxygenated hemoglobin. $\mathrm{SpO} 2$ expressed in term of $\mathrm{HbO} 2 \mathrm{and} \mathrm{Hb}$ as

$$
\left.\mathrm{SpO}_{2}=\frac{\mathrm{HbO}_{2}}{\mathrm{HbO}_{2}+\mathrm{Hb}}=(-45.06 * \mathrm{Z}+30.354) * \mathrm{Z}+98.845\right)
$$

Where $\mathrm{Z}$ is the ratio of red to infrared signals
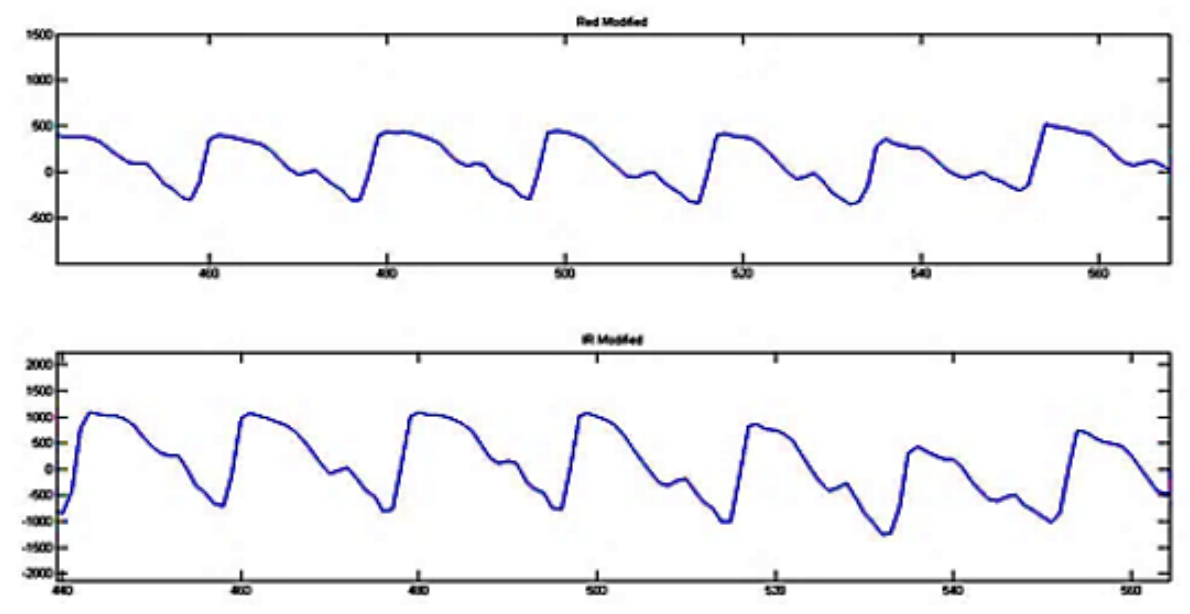

Fig 5. Red and Infrared components of the pulse oximetry

\subsection{Estimation of hemoglobin}

Figure 2 shows the block diagram for hemoglobin analysis, involving two LED's i.e. $660 \mathrm{~nm}$ red led and $940 \mathrm{~nm}$ infrared led wavelengths. Initially, before the finger is placed for calculation, light from both RED and IR LED's are incidents on the photodetector and their intensities are recorded as $I_{r 1}$ and $I_{i r 1}$ respectively. The two LEDs are turned on and off at an interval of every $250 \mathrm{~ms}$ using the microcontroller. The time for which the finger is placed is approximately 1-minute duration, during which the intensity of RED and IR LED's obtained from the photodetector, $I_{r}$ and $I_{i r}$ respectively are recorded. $I_{r}$ and $I_{i r}$ recorded waveforms as shown in Figure 5. Based on the intensity values of RED and IR LED's obtained. Optical density (OD) can be 
calculated using the following equation

$$
O D=\log \left(\frac{I_{r 1}}{I_{r}}\right)+\log \left(\frac{I_{i r 1}}{I_{i r}}\right)
$$

The hemoglobin is calculated using the below equation

$$
H b=c_{1} * O D^{3}+c_{2} * O D^{2}+c_{3} * O D+c_{4}
$$

Where $c_{1}, c_{2}, c_{3} \& c_{4}$ are constant coefficients $-1.173,19.28,-102.8,189.8$ respectively ${ }^{(37)}$.

\section{Results and Discussion}

A simulator operation performed on the individual volunteer and derived output of the circuit is shown in Figure 6a. The derived waveform shown in Figure $6 \mathrm{~b}$ are self-informative being the fact that the time stamp is present makes it very useful for doctors. Further analysis of the graphical data reveals the pulse rate, computed from the peak to peak time interval of any two consecutive positive or negative peaks. For a typical analysis the pulse rate, $\mathrm{SpO}_{2}$, and hemoglobin are algorithmically calculated using the data points within a time of 60 seconds. Successful utilization of these data, considering the number of peaks obtained, invariably gives the pulse and respiration rate of the subject under concern, which can then be store in databases for future analysis.

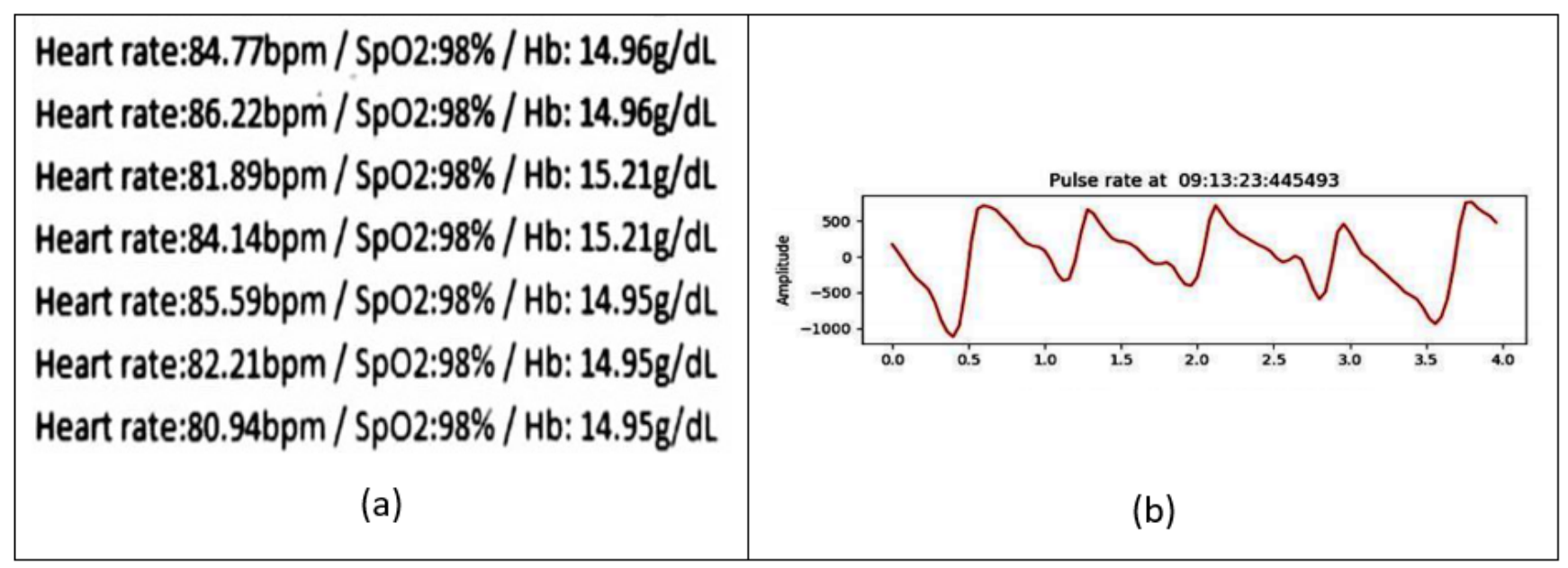

Fig 6. (a) Recorded parameters of heart rate, $\mathrm{S}_{p} \mathrm{O}_{2}$ and $\mathrm{Hb}$ (b) Pulse waveform with a timestamp

In this study, the volunteers are rested/relaxed for 3 - $5 \mathrm{~min}$ before acquiring the pulse. During the rested period volunteer's hemodynamic conditions might be more stable. After the rest, approximately 1 min duration is required to get accurate data from the subject and can be continuously monitored. Figure 6 shows a waveform of pulse and respiration rate obtained from a subject. The pulse rate, $\mathrm{SpO}_{2}$, and hemoglobin quantified parameters of 47 subjects under the mentioned conditions are tabulated in Table 1. Figure 7 shows a graphical representation of the hemoglobin concentration of healthy male and female subjects.

In the current study, the mean difference of $\mathrm{Hb}$ values between non-invasive and invasive techniques was found to be 0.12 to $1.0 \mathrm{~g} / \mathrm{dL}$. The obtained results were close to the invasive laboratory Hb measurements. The non-invasive approach holds a greater degree of accuracy when compared to the existing invasive methods. With the increase in usage of this new measurement technology, health care facilities can significantly reduce costs and improve care quality to a greater extent. The databases are updated every 30 seconds with a prime intention to reflect any parametric variation in pulse and hemoglobin of the subject. This essentially provides more flexibility and reliability to the data acquisition and management system, as even a minute variation in values is immediately updated in the database for analysis and report synthesis. 
Table 1. Vital Parameters Of Different Subjects

\begin{tabular}{lllllll}
\hline & Male & & \multicolumn{3}{c}{ Female } \\
\hline Parameters & Mean \pm SD & Max & Min & Mean \pm SD & Max & Min \\
\hline Pulse Rate (BPM) & $77.06 \pm 9.272$ & 101.40 & 66.90 & $76.47 \pm 9.326$ & 102.50 & 66.91 \\
$\mathrm{SpO}_{2}(\%)$ & $96.19 \pm 3.309$ & 98.77 & 83.73 & $96.54 \pm 2.262$ & 99.46 & 88.00 \\
Hemoglobin $(\mathrm{g} / \mathrm{dL})$ & $13.00 \pm 1.267$ & 15.70 & 10.98 & $12.17 \pm 1.307$ & 14.15 & 9.160 \\
\hline
\end{tabular}

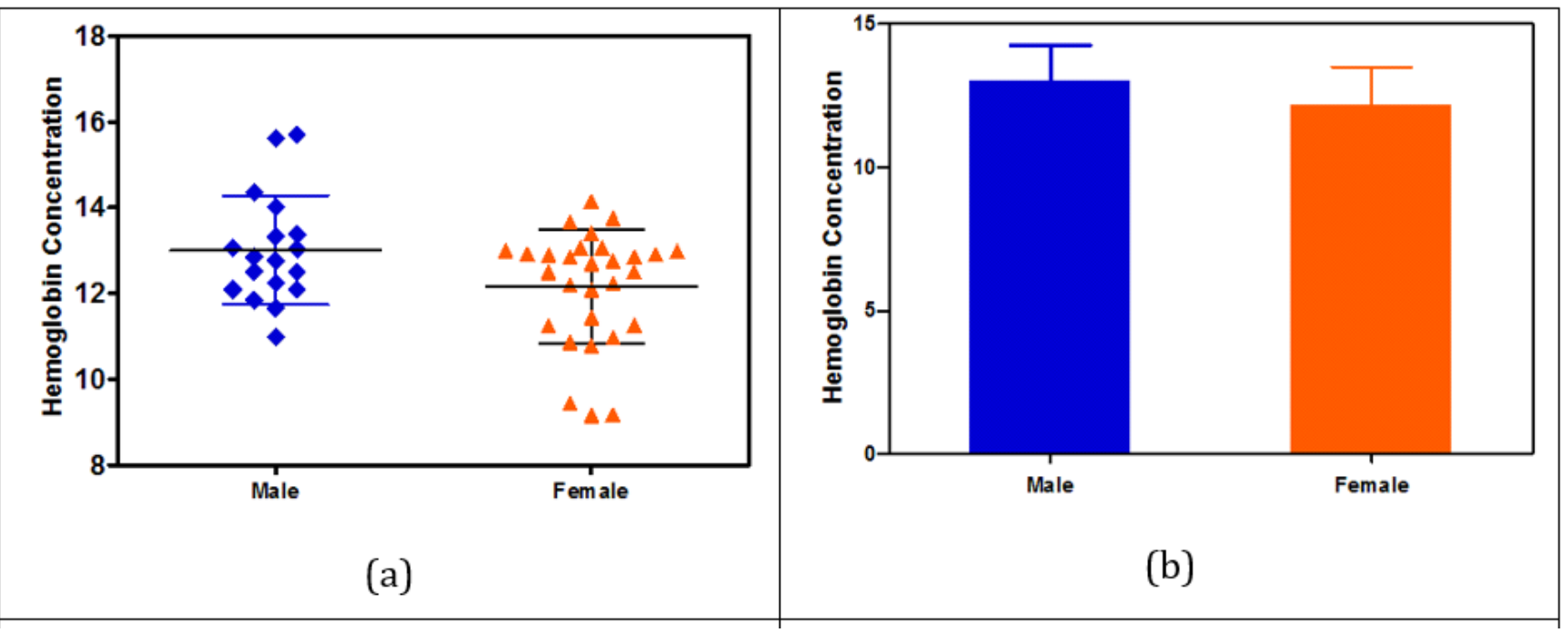

Fig 7. (a) Hemoglobin concentration of Male and Female (b) Comparison of Hb concentration in Male and Female subjects

\section{Conclusion}

In this study, a non-invasive device that measured heart rate, $\mathrm{SpO}_{2}, \mathrm{Hb}$ concentration using pulse oximetry in real-time with repeatability adds a major advantage to our approach. The hemoglobin values obtained from the designed prototype have shown significantly close to the values obtained from the clinical laboratory. Further, research is required to test more subjects to validate our approach.

\section{Acknowledgement}

We are thankful to the subjects of JSS Academy of Technical Education, Bengaluru, and anonymous reviewers.

\section{References}

1) Khandpur RS. Hand Book of Biomedical Instrumentation. New Delhi. Tata Mc Graw Hill publication. 2003.

2) Viana MB. Anemia and infection: a complex relationship. Revistabrasileira de hematologiae hemoterapia. 2011;33(2):90-92. Available from: http: //doi.org/10.5581/1516-8484.20110024.

3) Chaparro CM, Suchdev PS. Anemia epidemiology, pathophysiology, and etiology in low-and middle-income countries. Annals of the New York Academy of Sciences. 2019;1450(1):15-31. Available from: https://doi.org/10.1111/nyas.14092.

4) Organization WH. Haemoglobin concentrations for the diagnosis of anaemia and assessment of severity. 2011.

5) Hawkes C, Fanzo J. Nourishing the SDGs: Global nutrition report 2017. 2017. Available from: https://openaccess.city.ac.uk/id/eprint/19322.

6) Jain NP, Jain PN, Agarkar TP. An embedded, GSM based, multiparameter, realtime patient monitoring system and control - An implementation for ICU patients. In: 2012 World Congress on Information and Communication Technologies. 2012;p. 987-992. doi:10.1109/WICT.2012.6409218.

7) Wang J, Yu X, Ren L, Tang S. Design and development of ICU intelligent medicine management system based on MVC. In: 2016 IEEE International Conference on Bioinformatics and Biomedicine (BIBM). 2016;p. 1023-1027. doi:10.1109/BIBM.2016.7822662.

8) Yeldose A, Dhanyaja N, Jose JT, Anju SS. Integration of ICU data into electronic medical records-issues and solutions. In: 2013 IEEE Conference on Information \& Communication Technologies. 2013;p. 462-467. doi:10.1109/CICT.2013.6558140.

9) Joseph B, Haider A, Rhee P. Non-invasive hemoglobin monitoring. International Journal of Surgery. 2016;33:254-261. Available from: https://doi.org/10. 1016/j.ijsu.2015.11.048.

10) Joseph B, Pandit V, Aziz H, Kulvatunyou N, Zangbar B, Tang A, et al. Transforming hemoglobin measurement in trauma patients: noninvasive spot check hemoglobin. Journal of the American College of Surgeons. 2015;220(1):93-98. Available from: https://doi.org/10.1016/j.jamcollsurg.2014.09.022. 
11) Clemmesen CG, Palm H, Foss NB. Delay in detection and treatment of perioperative anemia in hip fracture surgery and its impact on postoperative outcomes. Injury. 2019;50(11):2034-2039. Available from: https://doi.org/10.1016/j.injury.2019.09.001.

12) Farris L, Szmuk P. Use of the Masimo Rainbow Noninvasive Hemoglobin Measurement for Children with Sickle Cell Disease. Journal of Investigative Medicine. 2011;59(2):520. Available from: https://hdl.handle.net/2152.5/1116.

13) Butwick A, Hilton G, Carvalho B. Non-invasive hemoglobin measurement in patients undergoing elective Caesarean section. British journal of anesthesia. 2012;108(2):271-278. Available from: https://doi.org/10.1093/bja/aer373.

14) Panda P, Sen M. Accuracy of haemoglobin estimation by non-invasive Pulse Co-oximetry method: A prospective observational study among Neonates, Children and Young Adults. The Journal of Medical Research. 2018;4(1):10-15. Available from: 10.31254/jmr.2018.4104.

15) Yoshida A, Saito K, Ishii K, Azuma I, Sasa H, Furuya K. Assessment of noninvasive, percutaneous hemoglobin measurement in pregnant and early postpartum women. Medical Devices. 2014;7:11-16. Available from: https://doi.org/10.2147/MDER.S54696.

16) Chaudhary R, Dubey A, Sonker A. Techniques used for the screening of hemoglobin levels in blood donors: current insights and future directions. Journal of blood medicine. 2017;8:75-82. Available from: 10.2147/JBM.S103788.

17) Pajares-Herraiz AL, Rodriguez-Gambarte JD, Eguia-Lopez B. A comparative study of three non-invasive systems for measurement of hemoglobin with hemocue system having coulter LH750 as reference value. Hematology \& Transfusion International Journal. 2015;1(3):68-74. Available from: 10.15406/htij.2015.01.00016.

18) Tang B, Yu X, Xu L, Zhu A, Zhang Y, Huang Y. Continuous noninvasive hemoglobin monitoring estimates timing for detecting anemia better than clinicians: a randomized controlled trial. BMC anesthesiology. 2019;19(1):1-8. Available from: https://doi.org/10.1186/s12871-019-0755-1.

19) Jeon KJ, Kim SJ, Park KK, Kim JW, Yoon G. Noninvasive total hemoglobin measurement. Journal of biomedical optics. 2002;7(1):45-51. Available from: https://doi.org/10.1117/1.1427047.

20) Gamal M, Abdelhamid B, Zakaria D, Dayem OAE, Rady A, Fawzy M, et al. Evaluation of noninvasive hemoglobin monitoring in trauma patients with low hemoglobin levels. Shock. 2018;49:150-153. Available from: 10.1097/SHK.0000000000000949.

21) Patino M, Schultz L, Hossain M, Moeller J, Mahmoud M, Gunter J, et al. Trending and accuracy of noninvasive hemoglobin monitoring in pediatric perioperative patients. Anesthesia \& Analgesia. 2014;119:920-925. Available from: 10.1213/ANE.0000000000000369.

22) Shah N, Osea EA, Martinez GJ. Accuracy of noninvasive hemoglobin and invasive point of care hemoglobin testing compared with a laboratory analyzer. International journal of laboratory hematology. 2014;36:56-61. Available from: https://doi.org/10.111/ijlh.12118.

23) Kallur JY, Bharat C, Shridevi SH, Shankar U. Efficacy of Pulse Co-oximeter in Hemoglobin Estimation: A noninvasive method. Annals of Pathology and Laboratory Medicine. 2017;4(5):A585-A590. Available from: 10.21276/APALM.1558.

24) Kumar R, Ranganathan H. Noninvasive sensor technology for total hemoglobin measurement in blood. Journal of Industrial and Intelligent Information. 2013;1(4):243-249. Available from: 10.12720/jiii.1.4.243-246.

25) Rochmanto RA, Zakaria H, Alviana RD, Shahib N. Non-invasive hemoglobin measurement for Anemia diagnosis. In 2017 th International Conference on Electrical Engineering. 2017;p. 1-5. Available from: 10.11591/eecsi.v4.1003.

26) Awada WN, Mohmoued MF, Radwan TM, Hussien GZ, Elkady HW. Continuous and noninvasive hemoglobin monitoring reduces red blood cell transfusion during neurosurgery: a prospective cohort study. Journal of clinical monitoring and computing. 2015;29:733-740. Available from: https: //doi.org/10.1007/s10877-015-9660-4.

27) Muady GF, Bitterman H, Laor A, Vardi M, Urin V, Ghanem-Zoubi N. Hemoglobin levels and blood transfusion in patients with sepsis in Internal Medicine Departments. BMC Infectious Diseases. 2016;16(569):1-8. Available from: https://doi.org/10.1186/s12879-016-1882-7.

28) Jr RDW, Mei Z, Mapango C, Jefferds MED. Methods and analyzers for hemoglobin measurement in clinical laboratories and field settings. Annals of the New York Academy of Sciences. 2019;1450(1):147-171. Available from: https://doi.org/10.1111/nyas.14124.

29) Barker SJ, Shander A, Ramsay MA. Continuous noninvasive hemoglobin monitoring: a measured response to a critical review. Anesthesia and analgesia. 2016;122:565-572. Available from: 10.1213/ANE.0000000000000605.

30) Cohen ZV, Haxha S, Aggoun A. Pulse oximetry optical sensor using oxygen-bound haemoglobin. Optics Express. 2016;24(9):10115-10131. Available from: 10.1364/oe.24.010115.

31) Chong AV, Terosiet M, Histace A, Romain O. Towards a novel single-LED pulse oximeter based on a multispectral sensor for IoT applications. Microelectronics Journal. 2019;88:128-136. Available from: 10.1016/j.mejo.2018.03.005.

32) Tsiakaka O, Gosselin B, Feruglio S. Source-Detector Spectral Pairing-Related Inaccuracies in Pulse Oximetry: Evaluation of the Wavelength Shift. Sensors. 2020;20(11):1-17. Available from: https://doi.org/10.3390/s20113302.

33) Macknet MR, Allard M, Applegate RL, Rook J. The accuracy of noninvasive and continuous total hemoglobin measurement by pulse CO-Oximetry in human subjects undergoing hemodilution. Anesthesia \& Analgesia. 2010;111(6):1424-1426. Available from: 10.1213/ANE.0b013e3181fc74b9.

34) Lamhaut L, Apriotesei R, Combes X, Lejay M, Carli P, Vivien B. Comparison of the accuracy of noninvasive hemoglobin monitoring by spectrophotometry $(\mathrm{SpHb})$ and $\mathrm{HemoCue}$ with automated laboratory hemoglobin measurement. The Journal of the American Society of Anesthesiologists. 2011;115(3):548554. Available from: https://doi.org/10.1097/ALN.0b013e3182270c22.

35) Lindner G, Exadaktylos AK. How noninvasive haemoglobin measurement with pulse CO-Oximetry can change your practice: an expert review. Emergency medicine international. 2013;701529. Available from: https://doi.org/10.1155/2013/701529.

36) Mcmurdy JW, Jay GD, Suner S, Trespalacios F, Crawford GP. Diffuse reflectance spectra of the palpebral conjunctiva and its utility as a noninvasive indicator of total hemoglobin. Journal of Biomedical Optics. 2006;11(1):14019. Available from: https://doi.org/10.1117/1.2167967.

37) Esenaliev R, Motamedi M, Prough D, United States patent US 6,751,490. Continuous optoacoustic monitoring of hemoglobin concentration and hematocrit. 2004.

38) Abay TY, Kyriacou PA. Photoplethysmography for blood volumes and oxygenation changes during intermittent vascular occlusions. Journal of Clinical Monitoring and Computing. 2018;32(3):447-455. Available from: 10.1007/s10877-017-0030-2.

39) Veerabhadrappa ST, Vyas AL, Anand S. Changes in heart rate variability and pulse wave characteristics during normal pregnancy and postpartum. International Journal of Biomedical Engineering and Technology. 2015;17(2):99-114. Available from: https://doi.org/10.1504/IJBET.2015.068045.

40) Timm U, Leen G, Lewis E, Mcgrath D, Kraitl J, Ewald H. Non-invasive optical real-time measurement of total hemoglobin content. Procedia Engineering. 2010;5:488-491. Available from: https://doi.org/10.1016/j.proeng.2010.09.153.

41) Elgendi M, Fletcher R, Liang Y, Howard N, Lovell NH, Abbott D, et al. The use of photoplethysmography for assessing hypertension. NPJ Digital Medicine. 2019;2(60):1-11. Available from: https://doi.org/10.1038/s41746-019-0136-7.

42) Shao J, Shi P, Hu S, Liu Y, Yu H. An optimization study of estimating blood pressure models based on pulse arrival time for continuous monitoring. Journal of Healthcare Engineering. 2020;p. 1078251. Available from: https://doi.org/10.1155/2020/1078251. 
43) Al-Sheikh MA, Ameen IA. Design of Mobile Healthcare Monitoring System Using IoT Technology and Cloud Computing. IOP Conference Series: Materials Science and Engineering. 2020;881:1-17. Available from: 10.1088/1757-899X/881/1/012113.

44) Lopez LJR, Aponte GP, Garcia AR. Internet of Things Applied in Healthcare Based on Open Hardware with Low-Energy Consumption. Healthcare Informatics Research. 2019;25(3):230-235. Available from: https://doi.org/10.4258/hir.2019.25.3.230.

45) Ali MM, Haxha S, Alam MM, Nwibor C, Sakel M. Design of Internet of Things (IoT) and Android Based Low Cost Health Monitoring Embedded System Wearable Sensor for Measuring SpO 2, Heart Rate and Body Temperature Simultaneously. Wireless Personal Communications. 2019;7:2449-2463. Available from: https://doi.org/10.1007/s11277-019-06995-7.

46) Kuncoro C, Luo WJ, Kuan YD. Wireless Photoplethysmography Sensor for Continuous Blood Pressure Biosignal Shape Acquisition. Journal of Sensors. 2020;p. 7192015. Available from: https://doi.org/10.1155/2020/7192015.

47) Liao LD, Wang Y, Tsao YC, Wang IJ, Jhang DF, Chuang CC, et al. Design and implementation of a multifunction wearable device to monitor sleep physiological signals. Micromachines. 2020;11(7):672. Available from: https://doi.org/10.3390/mi11070672.

48) Chowdhury MH, Shuzan MN, Chowdhury ME, Mahbub ZB, Uddin MM, Khandakar A. Estimating Blood Pressure from the Photoplethysmogram Signal and Demographic Features Using Machine Learning Techniques. . Sensors. 2020;20:3127. Available from: https://doi.org/10.3390/s20113127. 